\title{
COMUNICAÇÃO
}

\section{FONTES E NÍVEIS DE ÓLEOS NA ALIMENTAÇÃO DE CARPA COMUM (Cyprinus carpio L.) NA FASE DE CRESCIMENTO}

\author{
Sources and levels of oils in the feeding of common carp (Cyprinus carpio L.) \\ in the phase of growth
}

\author{
Álvaro Graeff', Amador Tomazelli²
}

\begin{abstract}
RESUMO
Testaram-se neste trabalho, quatro fontes de lipídios (algodão, canola, girassol e milho) e três níveis de inclusão (1, 3 e 5\%), na alimentação de carpas comum (Cyprinus carpio L.), incorporadas à dieta, na fase de engorda. Os peixes iniciaram com peso médio inicial de 26,6 $\pm 2,02 \mathrm{~g}$ e comprimento médio inicial $11,2 \pm 0,09 \mathrm{~cm}$ respectivamente para os tratamentos. As dietas foram formuladas dentro dos critérios para a espécie e para o sistema de produção, com ingredientes onde a proteína bruta e a energia ficassem estabilizadas em $28 \%$ e $2.800 \mathrm{kcal}$ de energia metabolizável $/ \mathrm{kg}$ de ração, e oferecida na quantidade de $1 \%$ do peso vivo ao dia, reajustado a cada 30 dias, na forma peletizada. Cada parcela experimental contou com seis peixes e utilizou-se um delineamento inteiramente casualizado, em esquema fatorial (4 fontes, 3 níveis) com 3 repetições. Os dados foram submetidos à análise de variância, teste $\mathrm{F}$, ao nível de significância de $5 \%$ e as médias comparadas pelo teste de Tukey. As variáveis peso médio final, comprimento médio final, conversão alimentar aparente e sobrevivência não apresentaram diferença significativa entre os tratamentos testados $(\mathrm{P}>0,05)$. Conclui-se, com base nos dados obtidos, que todas fontes e níveis de lipídios utilizados são eficientes na alimentação, devendo, portanto ser utilizado aquele que tiver valor econômico menor no momento. Também se concluiu que os diferentes tipos de rações experimentais não interferiram significativamente nas características do rendimento de carcaça e rendimento de filé.
\end{abstract}

Termos para indexação: Carpa comum, óleo de algodão, óleo de canola, óleo de girassol, óleo de milho, lipídios.

\begin{abstract}
In this research four lipids sources (cotton, canola, sunflower, corn) and three inclusion levels (1,3 and 5\%) were tested in common carp feeding (Cyprinus carpio L.) incorporated to the diet in the fattening stage. The fishes had start medium weight of 26,6 $\pm 2,02 \mathrm{~g}$ and start medium length of $11,2 \pm 0,09 \mathrm{~cm}$. Diets were formulated inside the criteria to the species and to the production system with ingredients in wich gross protein and energy were kept stable in $28 \%$ and 2800kcal of metabolizable energy/kg of ration. Diets were offered in the quantity of $1 \%$ of living weight per day readjusted every 30 days in the peletized form. Each experimental parcel comprised six fishes and used an entirely ramdomized design, in factorial ( 4 sources, 3 levels and 3 repetitions). The data were submitted to variance analisys $\mathrm{F}$ test to significant level of 5\%, and the mediums compared by the Tukey test. The variables final medium weight, final medium length, feed conversion ratio and survival, showed no significant differences between the tested treatments $(\mathrm{P}>0,05)$. Based on the collected data, all sources and lipids levels used are efficient in the feeding. Thus, the one with lower economical value should preferably be used.
\end{abstract}

Index terms: Common carp, lipids, cotton oil, canola oil, sunflower oil, corn oil.

(Recebido em 22 de junho de 2006 e aprovado em 17 de abril de 2007)

A piscicultura no estado de Santa Catarina encontra-se em franca expansão sendo as Carpas (Cyprinus carpio L.) a espécie mais cultivada. Apesar de sua carne não ser a melhor em termos culinários, mostra-se ascendente para a comercialização através de seus derivados e embutidos.

A aqüicultura se constitui em uma atividade pecuária promissora de grande importância, tanto econômica quanto nutricional. Essa atividade responde hoje em paises asiáticos a $85 \%$ da produção mundial (em quilos) e a $75 \%$ em valor financeiro (FAO, 1999).
Uma das principais exigências para qualquer espécie animal é a energia. Ela é essencial para a manutenção, crescimento e reprodução. A energia dietária para os peixes provém do uso da proteína, lipídeos e carboidratos, sendo, que o uso de cada classe desses nutrientes varia, normalmente, de acordo com o balanço da ração, das exigências do peixe e da espécie em questão (PEZZATO, 1997). Os lipídeos são a melhor fonte de energia para os peixes, seguido pela proteína e carboidratos (PEZZATO, 1999). A gordura é uma importante fonte de

\footnotetext{
'Médico Veterinário - Estação de Piscicultura da Epagri/UniPis - Empresa de Pesquisa e Extensão Rural de Santa Catarina/EPAGRI - Rua Abílio Franco, 1500 Bairro Bom Sucesso - Cx. P. 591 - 89500-000 - Caçados, SC - agraeff@epagri.sc.gov.br

'Engenheiro Agrônomo - Mestre - Estação Experimental da Epagri/EECd - Empresa de Pesquisa e Extensão Rural de Santa Catarina/EPAGRI Rua Abílio Franco, 1500 - Bairro Bom Sucesso - Cx. P. 591 - 89500-000 - Caçados, SC - amador@epagri.sc.gov.br
} 
energia que pode ser utilizada na alimentação dos peixes, pois é uma fonte de alimento facilmente encontrada no mercado e que fornece, além da energia, uma quantidade considerável de ácidos graxos essenciais (STEFFENS, 1987).

A fonte de gordura utilizada na ração pode influenciar significativamente no crescimento e na conversão alimentar dos peixes (MEURER et al., 1999). Óleos de origem vegetal, por exemplo, são boas fontes de gordura para peixes de clima tropical (WILSON, 1995). Além dos lipídios representarem uma fonte rica de energia, são também requeridos para manutenção da estrutura e função da membrana celular. Um outro fator a ser destacado é que os lipídeos incorporados nos tecidos dos peixes dependem do ingerido, ou seja, espelham o conteúdo dos alimentos consumidos (PEZZATO, 1999).

O balanceamento de nutrientes obtidos pelos peixes em seus ambientes naturais não ocorre quando os mesmos se encontram em ambientes confinados, quer pela ausência ou pela limitação de alimentos (PEZZATO, 1990). Em função disso, em cultivo intensivo, os peixes dependem da utilização de rações comerciais que satisfaçam as necessidades de nutrientes essenciais e de energia para garantir o desenvolvimento e a rentabilidade (CANTELMO, 1989). Contudo, as rações balanceadas utilizadas nos sistemas intensivos ainda têm custo relativamente alto, pois nelas são empregados, produtos e subprodutos de origem animal (GRAEFF, 1998).

No intuito de reduzir o custo das rações utilizadas em cultivos de peixes, pesquisadores da área de nutrição, têm dirigido suas atenções e trabalhos para a substituição de parte dos ingredientes de origem animal por ingredientes de origem vegetal, não descuidando-se do balanço de nutrientes essenciais, tanto pela suplementação com aminoácidos sintéticos quanto por complexos vitamínicosminerais (CANTELMO, 1989; PEZZATO, 1990).

Objetivou-se com este experimento avaliar o uso de diferentes fontes e níveis de óleos vegetais nas dietas sobre o desempenho produtivo, sobrevivência, conversão alimentar, rendimento de carcaça e rendimento de filé, na fase de crescimento da carpa comum (Cyprinus carpio L.).

O experimento foi realizado na Unidade de Piscicultura de Caçador/EPAGRI, em 36 aquários de cimento amianto, com capacidade para 1.000 litros de água, abastecidos individualmente com água proveniente do açude de abastecimento, numa vazão de 0,5 litros por minuto.

O período experimental foi de 180 dias, sendo iniciado em 01 de abril de 2005 e encerrado em 27 de setembro de 2005, com 7 dias de adaptação dos alevinos em cada parcela experimental.
O delineamento experimental foi inteiramente ao acaso, em um esquema fatorial de 4 × 3 , onde foram avaliada quatro fontes de óleos (algodão, canola, girassol e milho) e três níveis de inclusão $(1,3$ e $5 \%)$ e três repetições, com seis carpas comuns (Cyprinus carpio L.), em cada parcela experimental. $O$ peso médio inicial foi $26,6 \pm 2,02 \mathrm{~g}$ e o comprimento inicial de $11,2 \pm 0,09 \mathrm{~cm}$. As dietas foram peletizadas, formuladas, dentro dos critérios, para a espécie e sistema de produção (NRC, 1993), com ingredientes mantendo a proteína bruta e energia estabilizados em $28 \%$ e 2.800 kcal de energia metabolizável/kg de ração respectivamente, sendo oferecidas na quantidade de $1 \%$ do peso vivo ao dia, reajustado a cada 30 dias, sendo preservadas em geladeira, conforme o Quadro 1.

Amostras da água, que vem de um tanque de abastecimento, foram coletadas e analisadas semanalmente para as variáveis: transparência, com disco de Secchi; $\mathrm{pH}$ com peagâmetro marca Corning (PS-30); oxigênio dissolvido; nitrito; amônia total; dureza; alcalinidade; turbidez; e gás carbônico no Laboratório de Qualidade de Água/EPAGRI - Caçador.

As observações da temperatura da água foram realizadas diariamente com termômetro eletrônico - Thies Clima, sempre às 9:00 e às 15:00 horas, momento no qual os peixes recebiam a ração. Também verificou-se a temperatura ambiente com aparelho de corda, marca Wilh-Lambrech Gmbh Gottingen.

As avaliações dos peixes foram realizadas a cada 30 dias utilizando-se $100 \%$ dos peixes estocados, tomandose as medidas de comprimento total através de um ictiômetro e o peso individual em uma balança eletrônica, com precisão de $0,01 \mathrm{~g}$, marca Marte. Para a realização dessas atividades, os peixes foram sedados com $0,5 \mathrm{ml}$ de quinaldina para 15 litros de água. Ao final do experimento, foram efetuadas avaliações quantitativas, compreendendo as evoluções de crescimento em peso e comprimento, conversão alimentar aparente, sobrevivência e rendimento da carcaça e rendimento de filé.

A temperatura da água, durante o período experimental, manteve-se entre um mínimo de $8,7^{\circ} \mathrm{C}$ e máximo de $15,2^{\circ} \mathrm{C}$, no período da manhã, ficando a média do período em $12,6^{\circ} \mathrm{C}$ (Quadro 2). No período da tarde oscilou entre um mínimo de $14,0^{\circ} \mathrm{C}$ e um máximo de $22,1^{\circ} \mathrm{C}$ ficando a média em $17,0^{\circ} \mathrm{C}$. Note-se que as temperaturas foram inferiores às relatadas por Arrignon (1979) e Makinouchi (1980), que afirmaram haver um melhor crescimento das carpas entre $24,0^{\circ}$ e $28,0^{\circ} \mathrm{C}$;. Esse fato, aparentemente, não trouxe prejuízo ao crescimento dos alevinos. 
QUADRO 1 - Composição percentual das rações experimentais.

\begin{tabular}{|c|c|c|c|c|c|c|c|c|c|c|c|c|}
\hline \multirow{2}{*}{$\begin{array}{c}\text { Ingredientes } \\
\%\end{array}$} & \multicolumn{3}{|c|}{ Óleo de Algodão } & \multicolumn{3}{|c|}{ Óleo de Canola } & \multicolumn{3}{|c|}{ Óleo de Girassol } & \multicolumn{3}{|c|}{ Óleo de Milho } \\
\hline & 1 & 3 & 5 & 1 & 3 & 5 & 1 & 3 & 5 & 1 & 3 & 5 \\
\hline Farelo de soja & 32,0 & 30,0 & 33,0 & 32,0 & 30,0 & 33,0 & 32,0 & 30,0 & 33,0 & 32,0 & 30,0 & 33,0 \\
\hline Farinha de peixe & 20,0 & 22,0 & 19,8 & 20,0 & 22,0 & 19,8 & 20,0 & 22,0 & 19,8 & 20,0 & 22,0 & 19,8 \\
\hline Milho & 30,0 & 32,0 & 30,0 & 30,0 & 32,0 & 30,0 & 30,0 & 32,0 & 30,0 & 30,0 & 32,0 & 30,0 \\
\hline Farinha de mandioca & 8,0 & 3,0 & 0,2 & 8,0 & 3,0 & 0,2 & 8,0 & 3,0 & 0,2 & 8,0 & 3,0 & 0,2 \\
\hline Farelo de trigo & 5,0 & 5,0 & 7,0 & 5,0 & 5,0 & 7,0 & 5,0 & 5,0 & 7,0 & 5,0 & 5,0 & 7,0 \\
\hline Calcáreo calcítico & 3,0 & 4,0 & 4,0 & 3,0 & 4,0 & 4,0 & 3,0 & 4,0 & 4,0 & 3,0 & 4,0 & 4,0 \\
\hline Premix vitamínico $^{1}$ & 0,7 & 0,7 & 0,7 & 0,7 & 0,7 & 0,7 & 0,7 & 0,7 & 0,7 & 0,7 & 0,7 & 0,7 \\
\hline Premix mineral $^{2}$ & 0,3 & 0,3 & 0,3 & 0,3 & 0,3 & 0,3 & 0,3 & 0,3 & 0,3 & 0,3 & 0,3 & 0,3 \\
\hline Óleos & 1,0 & 3,0 & 5,0 & 1,0 & 3,0 & 5,0 & 1,0 & 3,0 & 5,0 & 1,0 & 3,0 & 5,0 \\
\hline \multicolumn{13}{|c|}{ Valores calculados } \\
\hline Energia metabolizável & 2.818 & 2.846 & 2.940 & 2.819 & 2.850 & 2.946 & 2.817 & 2.846 & 2.943 & 2.820 & 2.854 & 2.953 \\
\hline Proteína bruta & 27,9 & 28,0 & 28,4 & 27,9 & 28,0 & 28,4 & 27,9 & 28,0 & 28,4 & 27,9 & 28,0 & 28,4 \\
\hline Matéria seca & 85,2 & 82,2 & 80,6 & 85,2 & 82,2 & 80,6 & 85,2 & 82,2 & 81,3 & 85,2 & 82,2 & 80,6 \\
\hline Extrato Etéreo & 4,8 & 4,9 & 4,8 & 4,8 & 4,9 & 4,8 & 4,8 & 4,9 & 4,8 & 4,8 & 4,9 & 4,8 \\
\hline Cálcio & 2,4 & 3,0 & 2,8 & 2,4 & 3,0 & 2,8 & 2,4 & 3,0 & 2,8 & 2,4 & 3,0 & 2,8 \\
\hline Fósforo & 0,9 & 1,0 & 1,0 & 0,9 & 1,0 & 1,0 & 0,9 & 1,0 & 1,0 & 0,9 & 1,0 & 1,0 \\
\hline Relação EM/PB & 100,6 & 101,3 & 103,2 & 100,6 & 101,4 & 103,4 & 100,6 & 101,8 & 103,9 & 100,7 & 101,6 & 103,7 \\
\hline
\end{tabular}

1 - Composição por quilo de ração: Vit. A: 2.750 UI; Vit. D: 585 UI; Vit. E: 6 UI; Vit. K: 1 UI; Riboflavina: 1,5 mg; Ac. Pantotenico: 3,0 mg; Niacina: 9,0 mg; Vit. $B_{12}: 3,5 \mathrm{mcg}$; Colina: 63,0 mg; Biotina: 0,04 mcg; Ac. Fólico: 0,3 mg; Tiamina: $0,8 \mathrm{mg}$; Pirodoxina: $0,8 \mathrm{mg}$.

2 - Composição por quilo de ração: Mg: 17,0 ppm; S:140,0 ppm; Mn: 13,0 ppm; Cu: 0,1 ppm; Fé: 2,5 ppm; Zn: 2,2 ppm; Co: 0,2 ppm; I: 7,0 ppm

A temperatura média do ar durante o experimento oscilou entre um máximo de $16,7^{\circ} \mathrm{C}$ a um mínimo de $3,6^{\circ} \mathrm{C}$, ficando a média do período em $10,5^{\circ} \mathrm{C}$, considerada normal para o período no sul do Brasil e observado para a região (Quadro 2).

Na avaliação da qualidade da água, os parâmetros pH, oxigênio dissolvido, gás carbônico, dureza total, alcalinidade, amônia total e nitrito estavam dentro do preconizado por Arrignon (1979), Boyd (1976), Castagnolli (1992), Lukowicz (1982), Ordog \& Nunes (1988), Reid \& Wood (1976) e Tavares (1995), para a criação de Carpa comum (Cyprinus carpio L.) (Quadro 2).

A transparência permaneceu, durante todo período experimental, entre 18,0 e 52,0cm medida com auxílio de um disco de Secchi, indicando razoável densidade de plâncton (TAVARES, 1995). A turbidez, diretamente relacionada à transparência, permaneceu entre 29,0 e 40,0. Isso é conseqüência da presença de argilas coloidais, substâncias em solução, matéria orgânica dissolvida ou mesmo do plâncton no experimento (TAVARES, 1995).

Pela análise estatística dos dados não ocorreu interação significativa entre as fontes e níveis de óleo, assim como não foram observadas diferenças significativas ( $\mathrm{P}>0,05)$ para o comprimento médio final (Quadro 4), sobrevivência e conversão alimentar aparente dos peixes submetidos aos diferentes tratamentos.

O peso médio final dos peixes submetidos aos diferentes tratamentos demonstra variação alta e uma tendência de que o incremento de nível de óleo na ração corresponde a um decréscimo no peso (Quadro 3). Resultado semelhante obteve Meurer et al. (2002), avaliando o efeito de níveis de 3,0 a 12,0\% de óleos em rações para alevinos de tilápia do nilo, observando uma redução linear no ganho de peso dos animais. Resultados discordantes obtiveram Lanna et al. (2004), que em estudo realizado com alevinos de tilápia nilótica (Oreochromis niloticus), utilizando rações com óleo de soja em níveis de 0 e $10 \%$ e Melo et al. (1999) com alevinos de jundiá (Rhamdia quelen) com rações à base de banha suína, óleo de soja e canola, com inclusão de 5 e 10\%, não observaram diferenças significativas para crescimento, conversão alimentar aparente e ganho de peso. No entanto, observou-se acúmulo de gordura nas vísceras, em todos os tratamentos, na pesquisa, quando se passou de 1 para $5 \%$ de óleo apesar 
QUADRO 2 - Médias dos parâmetros limnológicos da água nas unidades experimentais em cada período do experimento.

\begin{tabular}{|lccccccc|}
\hline \multicolumn{1}{|c}{ Parâmetros limnológicos } & Abril & Maio & Junho & Julho & Agosto & Setembro & Média \\
\hline pH (potencial hidrogeniônico) & 7,2 & 7,5 & 7,0 & 7,1 & 6,8 & 7,2 & 7,1 \\
Oxigênio dissolvido $(\mathrm{mg} / \mathrm{L})$ & 6,7 & 6,4 & 6,2 & 6,8 & 6,6 & 6,7 & 6,5 \\
Gás Carbônico $(\mathrm{mg} / \mathrm{L})$ & 2,9 & 2,0 & 3,5 & 3,5 & 5,8 & 1,5 & 3,2 \\
Dureza total $(\mathrm{mg} / \mathrm{L} \mathrm{CaCO}$ ) & 20,0 & 20,0 & 20,0 & 21,0 & 21,0 & 22,0 & 20,6 \\
Alcalinidade $\left.(\mathrm{mg} / \mathrm{L} \mathrm{CaCO})_{3}\right)$ & 22,5 & 20,0 & 20,0 & 22,0 & 22,0 & 25,0 & 21,9 \\
Amônia total $(\mathrm{mg} / \mathrm{L})$ & 0,3 & 0,2 & 0,9 & 1,3 & 0,6 & 0,7 & 0,6 \\
Nitrito $(\mathrm{mg} / \mathrm{L})$ & 1,4 & 1,3 & 1,3 & 1,2 & 1,2 & 0,1 & 1,0 \\
Transparência $(\mathrm{cm})$ & 20,0 & 18,0 & 34,0 & 49,0 & 52,0 & 43,0 & 36,0 \\
Turbidez & 40,0 & 40,0 & 37,0 & 32,0 & 37,0 & 29,0 & 35,8 \\
Temperatura ambiente & 16,7 & 11,5 & 11,1 & 3,6 & 10,7 & 9,6 & 10,5 \\
Temperatura da água $(9.00 \mathrm{~h})$ & 15,2 & 14,8 & 13,2 & 8,7 & 11,9 & 12,2 & 12,6 \\
Temperatura da água $(15.00 \mathrm{~h})$ & 22,1 & 17,3 & 16,4 & 14,0 & 16,5 & 15,7 & 17,0 \\
\hline
\end{tabular}

da variação na composição química dos peixes, principalmente gordura, poder variar consideravelmente devido a fatores como: espécie, idade do animal, sexo, estação do ano e fatores ambientais (GERI et al., 1995; SHIRAI et al., 2002). Melo et al. (2002), avaliando a composição corporal de alevinos de Rhamdia quelen, alimentados com diferentes fontes de lipídios, obteve rendimento de carcaça entre 80,03 a $81,56 \%$ diferente desse trabalho que obteve rendimento médio de 83,5 a $84,0 \%$ (Quadro 5). Santos et al. (1995), avaliando o rendimento de filé do Hypostomus commersonii, em condições de alimentação natural obteve $20,88 \%$ resultado menor do que nesse trabalho que foram em média 34,5 a $35,1 \%$, dentro do esperado para a espécie (Quadro 5). Também Hayashi et al. (2000) utilizando óleos de soja, canola, girassol, linhaça, arroz e milho, na quantidade de $5 \%$ da dieta, para tilápia do nilo na fase inicial, concluíram que esses podem ser utilizados sem restrições. Boscolo et al. (2004), em trabalho semelhante, concluíram que pode ser utilizado $5,9 \%$ de gordura na ração para tilápias do nilo na fase de crescimento, sem causar prejuízo no desempenho e obtendo-se aumento no rendimento de carcaça e filé. Meer et al. (1997) avaliando o efeito de rações com diferentes níveis de gordura para alevinos de tambaqui (Colossoma macropomum) não observaram influência dos tratamentos sobre o ganho de peso. Já Hemrer \& Sandnes (1999) observaram melhora no desempenho do salmão (Salmo salar), alimentado com níveis crescentes de gordura na ração. Como o crescimento dos peixes é muito alto durante o estádio de desenvolvimento de larvas e alevinos, pois podem multiplicar várias vezes o seu peso diário, ao passo que um peixe em fase final de engorda ganha em média menos de $1 \%$ por dia do seu peso (HEPHER, 1988), há necessidade do uso de alimento que permita uma alta taxa de crescimento especifico. Esses resultados demonstram diferenças na habilidade de utilização de lipídios, entre as diversas espécies.

O comprimento médio final das repetições dos tratamentos (Quadro 4) demonstra coeficientes de variação muitos altos e uma tendência de que o incremento de nível de óleo na ração corresponde a uma estabilização no crescimento em comprimento. Resultado semelhante obteve Alami-Durante et al. (1991) com larvas de carpa comum (Cyprinus carpio) alimentadas com uma dieta incorporada ou não com $5 \%$ de óleo de fígado, onde com a inclusão, o comprimento médio final foi menor do que a dieta sem o óleo. Já Pozernick \& Wiegand (1997) utilizando $10 \%$ de óleo de fígado na dieta de alevinos de goldfish (Carassius auratus) concluiu que ao contrário de AlamiDurante et al. (1991), é benéfico o seu uso nessa espécie. Reafirmando as diferenças na habilidade de utilização de lipídios, entre as diversas espécies.

Pela análise estatística dos dados não ocorreu interação significativa entre as fontes e níveis de óleo, assim como não foram observadas diferenças significativas $(\mathrm{P}>0,05)$ para o rendimento de carcaça e rendimento de filé (Quadro 5), demonstrando que, independentes do tamanho do peixe, os percentuais de rendimento se equiparam. Diferente encontrou Melo et al. (2003), trabalhando com jundiás onde o rendimento de carcaça não apresentou diferença significativa para fontes testadas, porém para os níveis apresentou diferença significativa. 
QUADRO 3 - Peso médio inicial, peso médio final e ganho de peso da carpa comum (Cyprinus carpio L.), alimentadas com rações contendo diferentes fontes e níveis de óleos vegetais.

\begin{tabular}{|c|c|c|c|c|c|c|c|c|c|c|c|c|}
\hline \multirow{2}{*}{$\begin{array}{c}\text { Níveis } \\
\%\end{array}$} & \multicolumn{12}{|c|}{ Tratamentos } \\
\hline & \multicolumn{3}{|c|}{ Óleo de Algodão } & \multicolumn{3}{|c|}{ Óleo de Canola } & \multicolumn{3}{|c|}{ Óleo de Girassol } & \multicolumn{3}{|c|}{ Óleo de Milho } \\
\hline & $\mathrm{Pmi}^{1}$ & $\mathrm{Pmf}^{2}$ & $\mathrm{Gp}^{3}$ & $\mathrm{Pmi}^{1}$ & $\mathrm{Pmf}^{2}$ & $\mathrm{Gp}^{3}$ & $\mathrm{Pmi}^{1}$ & $\mathrm{Pmf}^{2}$ & $\mathrm{Gp}^{3}$ & $\mathrm{Pmi}^{1}$ & $\mathrm{Pmf}^{2}$ & $\mathrm{Gp}^{3}$ \\
\hline 1 & 26,6 & $68,0^{\mathrm{a}}$ & $41,4^{\mathrm{a}}$ & 26,6 & $67,8^{\mathrm{a}}$ & $41,2^{\mathrm{a}}$ & 26,6 & $51,4^{b}$ & $24,8^{\mathrm{c}}$ & 26,6 & $61,4^{\mathrm{ab}}$ & $34,8^{b}$ \\
\hline 3 & 26,6 & $50,0^{\mathrm{b}}$ & $23,4^{b}$ & 26,6 & $57,2^{\mathrm{a}}$ & $30,6^{\mathrm{a}}$ & 26,6 & $58,6^{\mathrm{a}}$ & $32,0^{\mathrm{a}}$ & 26,6 & $55,6^{\mathrm{a}}$ & $29,0^{\mathrm{a}}$ \\
\hline 5 & 26,6 & $58,7^{\mathrm{b}}$ & $32,1^{\mathrm{b}}$ & 26,6 & $72,2^{\mathrm{a}}$ & $45,6^{\mathrm{a}}$ & 26,6 & $53,1^{\mathrm{b}}$ & $26,5^{\mathrm{bc}}$ & 26,6 & $53,7^{\mathrm{b}}$ & $27,1^{\mathrm{bc}}$ \\
\hline
\end{tabular}

Médias na linha, seguidas de letras iguais, não diferem significativamente entre si $(\mathrm{P}<0,05)$ pelo teste Tukey $1-$ Pmi $=$ Peso médio inicial $(\mathrm{g})$

$2-\mathrm{Pmf}=$ Peso médio final $(\mathrm{g})$

$3-\mathrm{Gp}=$ Ganho de peso $(\mathrm{g})$

QUADRO 4 - Comprimento médio final (cm) dos tratamentos com níveis e fontes de lipídios.

\begin{tabular}{|ccccc|}
\hline Níveis & \multicolumn{4}{c|}{ Tratamentos } \\
\cline { 2 - 5 }$\%$ & Óleo de Algodão & Óleo de Canola & Óleo de Girassol & Óleo de Milho \\
\hline 1 & $15,3^{\mathrm{a}}$ & $14,7^{\mathrm{a}}$ & $13,9^{\mathrm{a}}$ & $14,7^{\mathrm{a}}$ \\
3 & $13,7^{\mathrm{a}}$ & $14,5^{\mathrm{a}}$ & $14,1^{\mathrm{a}}$ & $14,0^{\mathrm{a}}$ \\
5 & $14,3^{\mathrm{a}}$ & $15,9^{\mathrm{a}}$ & $14,4^{\mathrm{a}}$ & $14,2^{\mathrm{a}}$ \\
\hline
\end{tabular}

Médias na linha, seguidas de letras iguais, não diferem significativamente entre si $(\mathrm{P}<0,05)$ pelo teste Tukey.

QUADRO 5 - Percentagem sobre a carpa comum (Cyprinus carpio) inteira no rendimento de carcaça e rendimento de filé nos tratamentos com níveis e fontes de lipídios.

\begin{tabular}{|ccccccccccccc|}
\hline \multirow{2}{*}{$\begin{array}{c}\text { Níveis } \\
\text { \% }\end{array}$} & \multicolumn{10}{c|}{ Óleo de Algodão } & \multicolumn{10}{c|}{ Óleo de Canola } & \multicolumn{1}{c|}{ Óleo de Girassol } & \multicolumn{3}{c|}{ Óleo de Milho } \\
\hline & $\mathrm{Pmf}^{\mathrm{1}}$ & $\mathrm{RC}^{2}$ & $\mathrm{RF}^{3}$ & $\mathrm{Pmf}^{\mathrm{1}}$ & $\mathrm{RC}^{2}$ & $\mathrm{RF}^{3}$ & $\mathrm{Pmf}^{1}$ & $\mathrm{RC}^{2}$ & $\mathrm{RF}^{3}$ & $\mathrm{Pmf}^{1}$ & $\mathrm{RC}^{2}$ & $\mathrm{RF}^{3}$ \\
1 & $68,0^{\mathrm{a}}$ & $84,6^{\mathrm{a}}$ & $36,1^{\mathrm{a}}$ & $67,8^{\mathrm{a}}$ & $84,1^{\mathrm{a}}$ & $35,8^{\mathrm{a}}$ & $51,4^{\mathrm{b}}$ & $83,2^{\mathrm{a}}$ & $34,2^{\mathrm{a}}$ & $61,4^{\mathrm{ab}}$ & $84,1^{\mathrm{a}}$ & $35,4^{\mathrm{a}}$ \\
3 & $50,0^{\mathrm{b}}$ & $82,5^{\mathrm{a}}$ & $33,9^{\mathrm{a}}$ & $57,2^{\mathrm{a}}$ & $84,0^{\mathrm{a}}$ & $34,7^{\mathrm{a}}$ & $58,6^{\mathrm{a}}$ & $83,9^{\mathrm{a}}$ & $34,7^{\mathrm{a}}$ & $55,6^{\mathrm{a}}$ & $83,9^{\mathrm{a}}$ & $34,9^{\mathrm{a}}$ \\
5 & $58,7^{\mathrm{b}}$ & $83,7^{\mathrm{a}}$ & $34,8^{\mathrm{a}}$ & $72,2^{\mathrm{a}}$ & $84,1^{\mathrm{a}}$ & $34,9^{\mathrm{a}}$ & $53,1^{\mathrm{b}}$ & $83,6^{\mathrm{a}}$ & $34,8^{\mathrm{a}}$ & $53,7^{\mathrm{b}}$ & $83,4^{\mathrm{a}}$ & $34,6^{\mathrm{a}}$ \\
\hline
\end{tabular}

Médias na linha, seguidas de letras iguais, não diferem significativamente entre si $(\mathrm{P}<0,05)$ pelo teste Tukey

$1-\mathrm{Pmf}=$ Peso médio final $(\mathrm{g})$

$2-\mathrm{RC}=$ Rendimento de carcaça $(\%)$ somente sem visceras

$3-\mathrm{RF}=$ Rendimento de file $(\%)$ somente o file

A conversão alimentar aparente dos peixes foi 2,1; 2,2; 1,8 e 2,0 e também não foi influenciada pelos tratamentos e nem pelos níveis de inclusão nas dietas oferecidas, concordando com Chou \& Shiau (1996) e com os resultados de Stickney \& Wurtz (1986) para alevinos de tilápia e diferindo de Meer et al. (1997) e Meurer et al. (2002).

A taxa de sobrevivência $(66,3 ; 62,7 ; 77,3$ e 68,1), dos referidos tratamentos, está dentro do ocorrido em outros trabalhos na mesma região $(\mathrm{P}<0,05)$, diferente do que ocorreu com os resultados de Uliana et al. (2001), que trabalharam com larvas de jundiá com os mesmos tratamentos, com 5\% de inclusão de óleos na dieta e obtiveram índices acima de $85 \%$. Já em outro trabalho com uso de lecitina de soja a 2\%, também com larvas de jundiá, o mesmo autor obteve índices de sobrevivência muito baixos acarretando um efeito negativo. 
Conclui-se, com base nos resultados obtidos, que todas as fontes e níveis de óleos utilizados são eficientes na dieta oferecida para Carpas comum (Cyprinos carpio L.). Não influenciando no crescimento em peso e comprimento, sobrevivência e conversão alimentar. No entanto, deve-se levar em consideração o menor custo da fonte de lipídio no momento de sua utilização. Concluiuse, também, que os diferentes tipos de rações experimentais não interferiram significativamente nas características do rendimento de carcaça e rendimento de filé.

\section{REFERÊNCIAS BIBLIOGRÁFICAS}

ALAMI-DURANTE, H.; CHARLON, N.; ESCAFFRE, A. M. Supplementation of artificial diets for common carp. (Cyprinus carpio L.) larvae. Aquaculture, Amsterdam, v. 93, p. 167-175, 1991.

ARRIGNON, J. Ecologia Y piscicultura de águas dulces. Madrid: Mundi-Prensa, 1979. 365 p.

BOSCOLO, W. R.; HAYASHI, C.; MEURER, F.; FEIDEN, A.; WOLFF, L. Desempenho e características de carcaça de tilápias do nilo (Oreochromis niloticus L.) alimentadas com rações contendo diferentes níveis de gordura. Acta Scientiarum, Animal Sciences, [S.1.], v. 26, n. 4, p. $443-$ 447, 2004.

BOYD, C. E. Limme requirements and application in fishponds. Kyoto: [s.n.], 1976. 6 p.

CANTELMO, O. A. Nutrição de peixe e aqüicultura. In: HERNANDEZ, A. (Ed.). Cultivo de colossoma. Bogotá: Guadalupe, 1989. p. 85-91.

CASTAGNOLLI, N. Piscicultura de água doce. Jaboticabal: FUNEP, 1992. 189 p.

CHOU, B. S.; SHIAU, S. Y. Optimal dietary lipid level for growth of juvenile hybrid tilapia, Oreochromis niloticus $\mathrm{X}$ Oreochromis aureus. Aquaculture, Amsterdam, v. 143, n. 2, p. 185-195, 1996.

FAO. Aquaculture production statistics: 1988-1997. Roma, 1999. 203 p. (FAO fisheries circular, 815, rev. 11).

GERI, G. et al. Body traits and chemical composition of muscle in the common carp (Cyprinus carpio L.) as influenced by age and rearing environment. Aquaculture, Amsterdam, v. 129, p. 329-333, 1995.
GRAEFF, A. Efeito da substituição da proteína vegetal pelo uso de colágeno na alimentação de carpas (Cyprinus carpio L.). In: SIMPÓSIO BRASILEIRO DE AQUICULTURA, 10., 1998, Recife. Anais... Recife: [s.n.], 1998. p. 79-92.

HAYASHI, C.; SOARES, C. M.; MEURER, F.; SCHAMBER, C. R. Uso de diferentes óleos vegetais para tilápia do nilo (Oreochromis niloticus L.) na fase inicial. In: REUNIÃO DA SOCIEDADE BRASILEIRA DE ZOOTECNIA, 37., 2000, Viçosa. Anais... Viçosa: SBZ, 2000.

HEMRER, G. I.; SANDNES, K. Effect of dietary lipid level on muscle composition in atlantic salmon Salmo salar. Aquaculture Nutrition, Oxford, v. 5, p. 9-16, 1999.

HEPHER, B. Nutrition of pond fishes. Melbourne: Cambridge University, 1988. 388 p.

LANNA, E. A. T.; PEZZATO, L. E.; FURUYA, W. M.; VICENTINI, C. A.; CECON, P. R.; BARROS, M. M. Fibra bruta e óleo em dietas praticas para alevinos de tilápia do nilo (Oreochromis niloticus). Revista Brasileira de Zootecnia, Viçosa, v. 33, n. 6, p. 2177-2185, 2004.

LUKOWICZ, M. V. Intensive carp (Cyprinus carpio L.) is rearing in a farm pond in southern Germany and its effects on. Aquaculture Engineers, [S.l.], v. 1, n. 2, p. 121-137, 1982.

MAKINOUCHI, S. Criação de carpas em água parada. Informe Agropecuário, Belo Horizonte, v. 6, n. 67, p. 30-47, 1980.

MEER, M. B. et al. Effect of dietary lipid leven on protein utilization and size and proximate composition of body compartments of Colossoma macropomum (Curvier). Aquaculture Research, Oxford, v. 28, n. 6, p. 405-417, 1997.

MELO, J. F. B.; BOINJINK, C. de L.; RADUNZ NETO, J. Efeito da alimentação na composição química da carcaça do jundiá Rhamdia quelen. Biodiversidade Pampeana, Uruguaiana, v. 1, n. 1, p. 12-23, 2003.

MELO, J. F. B.; RADÜNZ NETO, J.; SILVA, J. H. S.; TROMBETTA, C. G. Influência de fontes de lipídios na dieta sobre o desempenho e deposição de nutrientes em juvenis de jundiá Rhamdia quelen. In: JORNADA ACADÊMICA INTEGRADA, 14., 1999, Santa Maria. Jornada Acadêmica Integrada da UFSM. Santa Maria: UFSM, 1999. 
MELO, J. F. B.; RADÜNZ NETO, J.; SILVA, J. H. S.; TROMBETTA, C. G. Desenvolvimento e composição corporal de alevinos de jundiá (Rhamdia quelen) alimentados com dietas contendo diferentes fontes de lipídios. Ciência Rural, Santa Maria, v. 32, n. 2, p. 323-327, 2002.

MEURER, F. et al. Lipídios na alimentação de alevinos revertidos de tilápia do nilo (Oreochromis niloticus, L.). Revista Brasileira de Zootecnia, Viçosa, v. 33, n. 2, p. 566573, 2002.

MEURER, F.; HAYASHI, C.; SOARES, C.; BOSCOLO, W. R. Níveis de gordura na alimentação de machos de tilápia nilótica (Oreochromis niloticus L.) revertidos sexualmente, na fase inicial. Anais do Simpósio Latino-americano de Aqüicultura, Campos de Jordão, v. 1, p. 348-357, 1999.

NATIONAL RESEARCH COUNCIL. Nutrient requirements of fish. Washington, DC, 1993. 103 p.

ORDOG, V.; NUNES, Z. M. P. Sensibilidade de peixes a amônia livre. In: SIMPÓSIO LATINO AMERICANO DE AQUICULTURA, 6.; SIMPÓSIO BRASILEIRO DE AQUICULTURA, 5., 1988, Florianópolis, SC. Anais... Florianópolis: ABRAq, 1988. p. 169-174.

PEZZATO, L. E. Alimentação de peixes: relação custo beneficio. In: REUNIÃO ANUAL DA SOCIEDADE BRASILEIRA DE ZOOTECNIA, 36., 1999, Porto Alegre. Anais... Porto Alegre: UFRGS, 1999. p. 107-118.

PEZZATO, L. E. Alimentos mais utilizados para peixes. In: CASTAGNOLli, N. (Ed.). Piscicultura. Jaboticabal: FUNEP, 1990. p. 87-99.

PEZZATO, L. E. O estabelecimento das exigências nutricionais das espécies de peixes cultivadas. In: SIMPÓSIO SOBRE MANEJO E NUTRIÇÃO DE PEIXES, 1., 1997, Piracicaba. Anais... Piracicaba: POTAFOS, 1997. p. 45-62.
POZERNICK, M.; WIEGAND, M. D. Use of canola oil in the feed of larval and juvenile goldfish, Carassius auratus (L). Aquaculture Research, Amsterdam, v. 28, p. 75-83, 1997.

REID, G. K.; WOOD, R. D. Ecology of Island waters and estuaries. New York: D. Van Nostrand, 1976. 485 p.

SANTOS, A. B.; MELO, J. F. B.; LOPES, P. R. S. Estudo da carcaça do cascudo Hypostomus commersonii, na região de Uruguaiana-RS/Brasil. In: ENCONTRO SUL BRASILEIRO DE AQÜICULTURA, 3.; ENCONTRO RIOGRANDENSE DETÉCNICOS EMAQÜICULTURA, 6., 1995, Uruguaiana. Anais... Uruguaiana: [s.n.], 1995. p. 7076.

SHIRAI, N. et al. Dietary and seasonal effects on the dorsal meat lipid composition of Japanese (Silurus asotus) and Thai catfish (Clarias macrocephalus) and hybrid Clarias macrocephalus and Clarias gariepinus. Comparative Biochemistry and Physiology Part A, [S.1.], v. 132, p. 609619,2002

STEFFENS, W. Principios fundamentales de la alimentación de los peces. Zaragoza: Acribia, 1987. 275 p.

STICKNEY, R. R.; WURTZ, W. A. Growth response of blue tilapias to selected levels of dietary menhaden and catfish oils. Prog. Fish-Culture, Bethesda, v. 48, p. 107-109, 1986.

TAVARES, L. H. S. Limnologia aplicada a aquicultura. Jaboticabal: FUNEP, 1995. 70 p.

ULIANA, O.; SILVA, J. H. S.; REZENDE NETO, J. Diferentes fonts de lipidios testadas na criação de larvas de jundiá (Rhamdia quelen), pisces, pimelodidae. Ciência Rural, Santa Maria, v. 31, n. 1, p. 129-133, 2001.

WILSON, R. P. Lipid nutrition of finfish: nutrition and utilization technology. Champain: AOAC, 1995. 